\title{
Study on Cold Chain Technology Investment Decision of Dual Channel Aquatic Supply Chain Under the Background of Maritime Silk Road
}

\author{
Miao-Ling Liu ${ }^{1}$, Bing-Cheng Yang ${ }^{2}$ \\ ${ }^{1}$ The School of Business, Lingnan Normal University, Zhanjiang, P. R. China \\ ${ }^{2}$ Sun Yat-sen Business School, Sun Yat-sen University, Guangzhou, P. R. China
}

Email address:

muriel_liu@163.com (Miao-Ling Liu), ybc_brighten@163.com (Bing-Cheng Yang)

\section{To cite this article:}

Miao-Ling Liu, Bing-Cheng Yang. Study on Cold Chain Technology Investment Decision of Dual Channel Aquatic Supply Chain Under the Background of Maritime Silk Road. European Business \& Management. Vol. 4, No. 3, 2018, pp. 80-87. doi: 10.11648/j.ebm.20180403.13

Received: June 15, 2018; Accepted: August 17, 2018; Published: September 17, 2018

\begin{abstract}
The Maritime Silk Road strategy brings more market opportunities to Zhanjiang's aquatic export trade, and further challenges to the quality and safety of aquatic products. As an effective technology to solve the problem of aquatic products safety in export trade, cold chain technology is designed to solve the problem of decision-making on cold chain technology in aquaculture enterprises. In this paper, a dual channel fishery supply chain is taken as the object. The investment model method is used to analyze the situation of the producer / retailer joint investment or non investment cold chain technology, and the influence of cold chain technology on the dual channel aquaculture supply chain investment and the problem of the coordination of the dual channel supply chain under the multiparty joint investment are studied. The research shows that the increase of the electronic commerce channel and the increase of food safety risk increases the sales price of electronic commerce channels and traditional retail channels, while the increase of the traditional retail channels of aquatic products corruption and food safety risks only increases the sale price of their own channels, and it will affect the sale of electronic commerce channels. If the cost of cold chain technology is lower than the cost of aquatic product corruption or food safety, cold chain technology can reduce the price of traditional retail channels and electronic commerce channels and increase the total market demand. This paper provides a new perspective for the application of cold chain technology, and also has a certain guiding significance for practice.
\end{abstract}

Keywords: Food Safety, Maritime Silk Road, Cold Chain Technology, Dual Channel Supply Chain, Investment Returns

\section{Introduction}

According to "China food safety development report (2016)", the study showed that the qualification rate of 13 types of bulk aquatic products, such as shrimp, was lower in five types of agricultural products, and the qualified rate was significantly higher than the other edible agricultural products, up to $97.1 \%$, higher than the ordinary level, so the aquatic products have been known as high incidence of safety accidents. The quality and safety of aquatic products is the focus of the industry. It is also an important part of China's strategy to ensure food safety. However, because of the dispersion of aquaculture, many channels of circulation, many and complex members of the aquatic supply chain, the unstable price elasticity of aquatic products is large, and the seasonal and perishable products of the aquatic products are strong and the products are perishable, which leads to the difficulty in the supervision of the supply chain of aquatic products, and the quality and safety questions are more easily taken place. At present, China is a producer / consumer and exporter of aquatic products. In particular, under the guidance of the strategy of the maritime Silk Road, customs actively carry out customs clearance reform to improve the efficiency of customs clearance, making the export volume of aquatic products 4 million 339 thousand and 400 tons in 2017, up by $2.4 \%$. With the improvement of people's living standard, consumer demand for aquatic products has increased and quality requirements for aquatic products have been raised. However, the rapid development of e-commerce has expanded the marketing channels and sales radius of aquatic products. At the same time, the strategy of Maritime Silk Road brings more market opportunities to aquatic products export trade, 
but also brings challenges to the quality of aquatic products. The implementation of cold chain management in the whole process of aquatic products is one of the methods to solve this problem. There are low quality seedlings, chemical residues, water pollution hazards in the aquatic product supply chain [1-3]. Even in the breeding process, it is possible for the farmers and processing enterprises to gain private benefits and excessive use of harmful hormones and antibiotics, leading to aquatic products safety. The whole problem is frequent [4]. Therefore, to solve these problems, a joint and efficient cold chain system is needed.

The use of cold chain transportation in the circulation of aquatic products can effectively inhibit microbial reproduction, so as to better control the quality of aquatic products and ensure the safety of aquatic products. From the perspective of supply, enterprises are cautious in investing because of the specificity of cold-chain facility assets. Some scholars have proposed to establish a standardized aquatic product traceability system to solve the problem of quality and safety, but at present, there are some problems in the traceability system of aquatic products in China [5, 6]. Food waste and losses in China were outlined, which is caused partly by the incomplete cold chain facilities in China. The problems relating to food preservation and safety in China were stated, in conjunction with rapid increase of China's frozen food production in recent years. [7] In addition to the foreign countries, the traceability system of aquatic products was established in Europe, Europe, Europe, Japan and Canada before 2002, and the United States also standardized the information labels of fish shellfish in aquatic products. In the study of agricultural product traceability technology investment will, $\mathrm{Wu}$ et al. (2013) believe that the expected benefits of food producers from the traceability system are one of the most important factors affecting corporate investment decisions [8]. and $\mathrm{Hu}$ et al.(2017) study that industrial chain coordination is the internal motive force to establish the traceability system of aquatic products, and the strengthening of the industrial chain relationship can promote the traceability system. He Jinget al. (2017) analyze the decision behavior of the traceability system of aquatic products from the view of food supply and demand network, and think that the optimal strategy of ensuring production safety under independent decision making is the best strategy, but under the common decision, the cooperative establishment of traceability system makes the food supply chain reach the best and the income is higher than the independent decision [9]. For the cold chain technology, Liu yang (2018) analyses the current situation of cold chain logistics of fresh agricultural products in China, analyzes the cold chain logistics facilities and technology of fresh agricultural products, and the disadvantages of the market are serious, and the investment and construction of the cold chain logistics infrastructure should be increased on the whole [10]. However, the cold chain technology itself still needs to be improved, so the improvement of the cold chain technology is also a topic of great concern in the academic circle. For example, Xinqing Xiao (2016) uses observation, interview and literature review to analyze the demand and cognition of cold chain system, and put forward the intelligent traceability system of wireless sensor, which can be tracked and monitored [11], The real-time temperature fluctuation and quality of the water measuring product. Meanwhile, Cold chain effect and product variability will affect the quality attributes of products [12]. If cold chain technology consumes too much energy and can not guarantee the perfect quality of food [13]. Therefore, the concept of ultracold chain is proposed. These cold chain technologies can better reduce food spoilage, but a lot of investment is needed. The management of cold chain temperature is also very important. According to the investigation and research, the cold chain temperature abuse appears in different countries, especially in developed countries. Therefore, it is necessary to strengthen the control and management of the temperature in the cold chain of food [14]. Considering the cost and profit of cold chain, M Wang (2018) established the optimization model of fresh food supply chain [15]. In order to maximize member profits, the optimal investment level and optimal pricing of cold chain construction were determined. The results showed that the advantage strategy of cooperative cold chain and synergistic pricing of supply chain was shown. However who will invest in building cold chain system among the members of the supply chain? The current investment research does not solve these problems. Therefore, based on the maritime silk road background, this article is study on cold chain technology investment decision of dual channel aquatic supply chain under the background of maritime silk Road. To discuss this problem has the theory significance and practical significance to explore channel members' investment strategies and corresponding changes in earnings.

\section{Problem Description}

This paper considers the problem of food safety management and studies the influence and coordination of investment cold chain technology on the investment income of dual channel supply chain enterprises. It is assumed that the participants in the aquatic supply chain are rational and pursue the maximization of their own income. The life cycle of aquatic products is short, perishable, and the cost of unit production is $c$. Manufacturers sell mainly through e-commerce channels $(e)$ and traditional retail channels $(t)$. In the aquatic supply chain, both the supplier and the retailer are directly exposed to the consumer market. The information of the market demand for aquatic products and the decision-making information of the participants in the supply chain are more familiar. The two are competing with the game. Before the sale of aquatic products, the best wholesale price $(w)$ and electronic commerce channel stock $(x)$ are determined by the manufacturer, and the retailer is the followers, and the quantity of the order is determined according to the wholesale price and the market demand $(y)$ made by the producer.

In order to meet market demand, manufacturers and retailers will adjust their stocking and purchase volume based 
on past experience. Considering the product and logistics transportation of the dual channel supply chain, it is unavoidable that there is a certain ratio of aquatic product deterioration or food safety. The products are not sold or faced with the risk of food safety compensation during the sale. The food safety risks of the producers and retailers are divided into each channel ( $a_{m}$ and $a_{s}$ ), indicating the change of the aquatic products in various channels. The ratio of the number of food safety problems to the actual sales volume is $a_{m}>0$ or $a_{s}<0$. Food safety problems may cause damage to the brand image, may cause economic losses, assuming the probability of economic $\operatorname{loss} \theta$, economic loss $l$. The relationship between the actual sales volume of aquatic products $\left(q_{e}, q_{t}\right)$ and the volume of stocking $(x)$ and order quantity $(y)$ in e-commerce channels and traditional retail channels is $\mathrm{x}=\left(1+\mathrm{a}_{\mathrm{m}}\right) \mathrm{q}_{\mathrm{e}}, y=\left(1+a_{s}\right) q_{t}$. When manufacturers or retailers invest in cold chain technology, make $a_{m}=0$ or $a_{s}$ $=0$. In addition, the use of traceability systems will increase supply chain costs, including cold chain infrastructure. As the sales of the aquatic products are large, the electricity and related facilities are more used in the process, and the basic facilities can be reused, so the cost of the cold chain infrastructure is the main factor restricting the application of traceability. At the same time, the cost of infrastructure is considered, and the cost of the infrastructure is considered, and the cost of each unit of aquatic products $\left(c_{f}\right)$ is assumed to be shared.

In the aquatic product supply chain, the e-commerce channel and the traditional retail channel serve the same market, causing a competition relationship between them. $q_{e}$ and $q_{t}$ is the potential demand of the aquatic products, $\rho$ is the market share of the traditional retail channels, $\rho Q$ is the potential demand of the traditional retail channels, (1- $\rho) Q$ is the potential demand of the electronic commerce channels, and $\beta$ is the assumption that the consumer is sensitive to the price of aquatic products. $\varepsilon$ is the sensitivity coefficient which the cross elasticity coefficient between the two channels. When the manufacturer and the retailer sell the product at the cost price, the $\rho Q-(\beta-\varepsilon) c>0$ and (1- $\rho) Q-(\beta-\varepsilon) c>0$ must be set up if the sales of the dual channels are guaranteed. Based on this, the linear reverse demand function of aquatic products in e-commerce channels and traditional retail channels is

$$
\begin{aligned}
& q_{e}=(1-\rho) Q-\beta p_{e}+\varepsilon p_{t} \\
& q_{t}=\rho Q-\beta p_{t}+\varepsilon p_{e}
\end{aligned}
$$

Producers and retailers make independent decisions and maximize their interests when making decisions. Manufacturers wholesale and online sales of aquatic products, so manufacturers make retailers' wholesale prices $(w)$ and e-commerce prices $\left(p_{e}\right)$ to maximize their own profits; then retailers make their sales prices in accordance with wholesale prices to maximize profits. This article is divided into two kinds of investment cold chain and non investment cold chain. Based on this, we will discuss the investment decision-making behavior of cold chain technology in dual channel aquatic supply chain from two perspectives.

\section{Model Establishment and Analysis}

\subsection{Manufacturers and Retailers Do Not Invest in Cold Chain Technology}

When both the manufacturer and the retailer do not invest in cold chain technology, the two parties have a certain proportion of food corruption loss or food safety risk. At this time, the profit function of the manufacturer and the retailer, the profit function of the manufacturer mainly includes the profit obtained by the manufacturer from the traditional retail channel, and the profit obtained by the electronic commerce channel. The loss of food corruption and food safety risks; the profit function of the retailer mainly includes the profits of the retailer's sales products, the deterioration of food corruption and the risk of food safety, respectively:

$$
\begin{gathered}
\prod_{m}^{N N}=(w-c)\left(1+\alpha_{s}\right) q_{t}+\left(p_{e}-c\right) q_{e}-\alpha_{m} q_{e}(c-s)-\theta l \\
\prod_{s}^{N N}=\left(p_{t}-w\right) q_{t}-\alpha_{s} q_{t} w-\theta l
\end{gathered}
$$

The formula (2) is brought into the type (4):

$$
\Pi_{s}^{N N}=\left(p_{t}-w-\alpha_{s} w\right)\left(\rho Q-\beta p_{t}+\varepsilon p_{e}\right)-\theta l
$$

$\frac{\partial^{2} \prod_{s}^{N N}}{\partial p_{t}^{2}}=-2 \beta<0$, The formula (5) has the unique optimal solution to maximize its value. The optimal solution is obtained, and the retailer's response function is:

$$
p_{t}^{*}=\frac{\rho Q+p_{e} \varepsilon+w \beta\left(1+\alpha_{s}\right)}{2 \beta}
$$

The formula (1) and the formula (6) are substituted (3), and the formula the two order partial derivatives are obtained:

$$
\begin{aligned}
& A=\left[\begin{array}{cc}
\left(1+\alpha_{s}\right)\left(-\beta-\beta \alpha_{s}\right) & \frac{1}{2} \varepsilon\left(1+\alpha_{s}\right) \\
\frac{1}{2} \varepsilon\left(1+\alpha_{s}\right) & 0
\end{array}\right] \\
& \Pi_{\mathrm{s}}^{\mathrm{NN}}=\left(\mathrm{c}^{2} \beta^{2}-2 \mathrm{c}^{2} \beta \varepsilon+\mathrm{c}^{2} \varepsilon^{2}-16 \beta \theta \mathrm{l}-2 \mathrm{cQ} \beta \rho+2 \mathrm{cQ} \varepsilon \rho\right. \\
& +Q^{2} \rho^{2}+c^{2} \varepsilon^{2} \alpha_{m}^{2}+2 c \beta(c \beta-c \varepsilon-Q \rho) \alpha_{s} \\
& +\mathrm{c}^{2} \beta^{2} \alpha_{\mathrm{s}}^{2} \\
& \left.+2 c \varepsilon \alpha_{m}\left(-c \beta+c \varepsilon+Q \rho-c \beta \alpha_{s}\right)\right) / 16 \beta
\end{aligned}
$$

It is known by the hather matrix, $A_{1}=-\left(1+\alpha_{s}\right)\left(\beta+\beta \alpha_{s}\right)$ $<0, A_{2}=-\frac{1}{4} \varepsilon\left(1+\alpha_{s}\right)<0$, It is shown that $\mathrm{A}$ is a negative definite matrix, so $\prod_{m}^{N N}$ is a joint concave function of sum $w$ and $p_{e}$, and the function has unique solution to maximize the function. Accordingly, $w$ and $p_{e}$ the first derivative of the 
function is obtained, the optimal wholesale price of the manufacturer and the optimal selling price of the electricity

supplier channel are obtained:

$$
\begin{gathered}
\mathrm{w}^{\mathrm{NN}}=\left(\left(1+\alpha_{\mathrm{s}}\right)\left(\beta^{2}-\varepsilon^{2}\right) \mathrm{c}+(\varepsilon+\beta \rho-\varepsilon \rho) \mathrm{Q}+\mathrm{c}\left(\beta^{2}-\varepsilon^{2}\right)\right) / 2\left(1+\alpha_{\mathrm{s}}\right)\left(\beta^{2}-\varepsilon^{2}\right) \\
\mathrm{p}_{\mathrm{e}}^{\mathrm{NN}}=\left(\mathrm{c}\left(\beta^{2}-\varepsilon^{2}\right)+\mathrm{Q}(\beta-\beta \rho+\varepsilon \rho)+\mathrm{c}\left(\beta^{2}-\varepsilon^{2}\right) \alpha_{\mathrm{m}}\right) / 2\left(\beta^{2}-\varepsilon^{2}\right)
\end{gathered}
$$

The best selling price of the retail channel is:

$$
\mathrm{p}_{\mathrm{t}}^{\mathrm{NN}}=\begin{gathered}
\left(\mathrm{c} \beta\left(\beta^{2}-\varepsilon^{2}\right) \alpha_{\mathrm{s}}+\mathrm{c} \beta^{2}+2 \mathrm{Q} \beta \varepsilon+\mathrm{c} \beta^{2} \varepsilon-\mathrm{c} \beta \varepsilon^{2}-c \varepsilon^{2}\right. \\
\left.+3 Q \beta^{2} \rho-2 Q \beta \varepsilon \rho-Q \varepsilon^{2} \rho+\mathrm{c} \beta\left(\beta^{2}-\varepsilon^{2}\right) \alpha_{\mathrm{s}}\right)
\end{gathered}
$$

The demand for products in e-commerce channels and traditional channels is

$$
\begin{gathered}
\mathrm{q}_{\mathrm{t}}^{\mathrm{NN}}=\left(-\mathrm{c} \beta+\mathrm{c} \varepsilon+\mathrm{Q} \rho+\mathrm{c} \varepsilon \alpha_{\mathrm{m}}-\mathrm{c} \beta \alpha_{\mathrm{s}}\right) / 4 \\
\mathrm{q}_{\mathrm{e}}^{\mathrm{NN}}=\left(2 \mathrm{Q} \beta-2 \mathrm{c} \beta^{2}+\mathrm{c} \beta \varepsilon+\mathrm{c} \varepsilon^{2}-2 \mathrm{Q} \beta \rho+\mathrm{Q} \varepsilon \rho+\mathrm{c}\left(\varepsilon^{2}-2 \beta^{2}\right) \alpha_{\mathrm{m}}+\mathrm{c} \beta \varepsilon \alpha_{\mathrm{s}}\right) / 4 \beta
\end{gathered}
$$

The manufacturer's stock and order quantity are:

$$
\begin{gathered}
\mathrm{x}^{\mathrm{NN}}=\begin{array}{c}
\left(1+\alpha_{\mathrm{m}}\right)\left(2 Q \beta-2 \mathrm{c} \beta^{2}+\mathrm{c} \beta \varepsilon+\mathrm{c} \varepsilon^{2}-2 Q \beta \rho+Q \varepsilon \rho+\mathrm{c}\right. \\
\left.\left(\varepsilon^{2}-2 \beta^{2}\right) \alpha_{\mathrm{m}}+\mathrm{c} \beta \varepsilon \alpha_{\mathrm{s}}\right)
\end{array} \\
\mathrm{y}^{\mathrm{NN}}=\begin{array}{c}
\left(1+\alpha_{\mathrm{s}}\right)\left(2 Q \beta-2 \mathrm{c} \beta^{2}+\mathrm{c} \beta \varepsilon+\mathrm{c} \varepsilon^{2}-2 Q \beta \rho+Q \varepsilon \rho+\mathrm{c} / 4 \beta\right. \\
\left.\left(\varepsilon^{2}-2 \beta^{2}\right) \alpha_{\mathrm{m}}+\mathrm{c} \beta \varepsilon \alpha_{\mathrm{s}}\right)
\end{array}
\end{gathered}
$$

The profit of the retailer and the manufacturer is:

$$
\begin{gathered}
\Pi_{\mathrm{s}}^{\mathrm{NN}}=\left(\mathrm{s}^{2} \alpha_{\mathrm{m}}{ }^{2} \varepsilon^{2}+\mathrm{c}^{2}\left(\left(1+\alpha_{\mathrm{s}}\right) \beta-\left(1+\alpha_{\mathrm{m}}\right) \varepsilon\right)^{2}-161 \beta \theta-2 \mathrm{Q} \text { s } \alpha_{\mathrm{m}} \varepsilon \rho+\mathrm{Q}^{2} \rho^{2}+2 \mathrm{c}\left(\left(1+\alpha_{\mathrm{s}}\right) \beta-\left(1+\alpha_{\mathrm{m}}\right) \varepsilon\right)\left(\mathrm{s} \alpha_{\mathrm{m}} \varepsilon-\mathrm{Q} \rho\right)\right) / 16 \beta \quad(15) \\
\Pi_{\mathrm{m}}^{\mathrm{NN}}=\left(-8 \theta \mathrm{l}-\frac{2 \mathrm{c} \alpha_{\mathrm{m}}\left(2 \mathrm{Q} \beta-2 \mathrm{c} \beta^{2}+\mathrm{c} \beta \varepsilon+\mathrm{c} \varepsilon^{2}-2 \mathrm{Q} \beta \rho+\mathrm{Q} \varepsilon \rho+\mathrm{C}\left(\varepsilon^{2}-2 \beta^{2}\right) \alpha_{\mathrm{m}+\mathrm{c} \beta \varepsilon \alpha_{\mathrm{s}}}+\frac{1}{\beta^{3}-\beta \varepsilon^{2}}\left(\mathrm{c}\left(\varepsilon^{2}-\beta^{2}\right)+\mathrm{Q}(\beta-\beta \rho+\varepsilon \rho)+\mathrm{c}\left(\beta^{2}-\right.\right.\right.}{\beta} \begin{array}{c}
\left.\varepsilon^{2}\right) \alpha_{\mathrm{m}}\left(2 \mathrm{Q} \beta-2 \mathrm{c} \beta^{2}+\mathrm{c} \beta \varepsilon+\mathrm{c} \varepsilon^{2}-2 \mathrm{Q} \beta \rho+\mathrm{Q} \rho+\mathrm{c}\left(\varepsilon^{2}-2 \beta^{2}\right) \alpha_{\mathrm{m}}+\mathrm{c} \beta \varepsilon \alpha_{\mathrm{s}}\right)+ \\
\frac{\left(\mathrm{c} \beta-\mathrm{c} \varepsilon-\mathrm{Q} \rho-\mathrm{c} \varepsilon \alpha_{\mathrm{m}}+\mathrm{c} \beta \alpha_{\mathrm{s}}\right)\left(\mathrm{c}\left(\beta^{2}-\varepsilon^{2}\right)+\mathrm{Q}(\varepsilon(\rho-1)-\beta \rho)+\mathrm{c}\left(\beta^{2}-\varepsilon^{2}\right) \alpha_{\mathrm{s}}\right.}{\beta^{2}-\varepsilon^{2}} / 8
\end{array}\right.
\end{gathered}
$$

Based on the above analysis, the following hypotheses are put forward as:

$$
\begin{gathered}
\text { Hypothesis } 1 \frac{\partial \alpha_{s}}{\partial \omega^{N N}}>0, \frac{\partial \alpha_{s}}{\partial p_{e}^{N N}}>0, \frac{\partial \alpha_{s}}{\partial p_{t}^{N N}}>0, \frac{\partial \alpha_{s}}{\partial q_{e}{ }^{N N}}>0 \\
\frac{\partial \alpha_{s}}{\partial q_{t}^{N N}}>0, \frac{\partial \alpha_{m}}{\partial q_{t}^{N N}}>0, \frac{\partial \alpha_{m}}{\partial p_{t}^{N N}}>0, \frac{\partial \alpha_{m}}{\partial q_{e}^{N N}}>0, \frac{\partial \alpha_{m}}{\partial q_{t}^{N N}}>0
\end{gathered}
$$

To prove hypothesis 1 , the increase of food corruption loss or the risk of food safety risk will increase the wholesale price of aquatic products, the sales price of retail channels and the sales price of electronic commerce channels will reduce the sales volume of retail channels, but have no direct impact on the sales of electronic commerce channels; The loss of food corruption or the risk of food safety increases, which makes the sale price of e-commerce channels rise and sales decrease, which makes the sales volume increase and sales price decrease. Because of the risk of food loss or food safety in various channels, the cost and price of sales channels have been raised, resulting in a decrease in sales volume in this channel. At the same time, the food corruption loss or food safety risk of e-commerce channels has made the sale price of e-commerce channels and traditional retail channels rise, while the traditional retail channels of food corruption and food safety risk only affect the sales price of retail channels. It shows that the risk of food corruption and food safety in direct selling channels will indirectly affect the price of aquatic products through wholesale prices, thereby improving the cost of retail channels. Therefore, food corruption and food safety risks increase the sales price of aquatic products, and then reduce the sales volume of products and affect the efficiency of the whole supply chain of aquatic products. Therefore, the impact of food corruption and food safety risks on the dual channel supply chain needs to be reduced.

\subsection{Manufacturers and Retailers Jointly Invest Cold Chain Technology}

When the manufacturer and the retailer jointly invest the cold chain technology, the food corruption and the food safety risk of the dual channel supply chain are reduced. At this time, the demand of the dual channel market is equal to the quantity of the manufacturer and the order quantity of the retailer. In the process of production, manufacturers use cold chain technology to store and transport, and then distribute aquatic products to retail channels and e-commerce channels according to the quantity of retailers' orders and the demand for e-commerce channels. The cost of the cold chain technology is borne by the manufacturer in the manufacturer's link, while the retailer will compensate the technical cost of the cold chain by part of the profits from the retailer. In 
addition, the producer is the leader of the dual channel supply chain. In order to maximize the overall revenue of the supply chain, the manufacturer makes a contract by making a contract to make the retailer build together. In order to provide contract standards for manufacturers, this paper continues to explore the joint investment situation of dual channel supply chain.

In the case of centralized decision making by the producer and retailer, the producer and retailer are a whole, which aims at maximizing the overall profit of the supply chain. Therefore, the income function of the centralized decision is as follows:

$$
\Pi^{Y Y}=\left(p_{t}-c\right) q_{t}+\left(p_{e}-c\right) q_{e}-c_{f}\left(q_{t}+q_{e}\right)
$$

The optimal selling price and sales volume of e-commerce channels and retail channels are as follows:

$$
\begin{gathered}
\mathrm{p}_{\mathrm{e}}=\left(\mathrm{c}\left(\beta^{2}-\varepsilon^{2}\right)+\mathrm{Q}(\beta-\beta \rho+\varepsilon \rho)+\left(\beta^{2}-\varepsilon^{2}\right) \mathrm{c}_{\mathrm{f}}\right) / 2\left(\beta^{2}-\varepsilon^{2}\right) \\
\mathrm{p}_{\mathrm{t}}=\left(\mathrm{c}\left(\beta^{2}-\varepsilon^{2}\right)+\mathrm{Q}(\varepsilon+\beta \rho-\varepsilon \rho)+\left(\beta^{2}-\varepsilon^{2}\right) \mathrm{c}_{\mathrm{f}}\right) / 2\left(\beta^{2}-\varepsilon^{2}\right) \\
\mathrm{q}_{\mathrm{t}}=\left(\mathrm{c}(\varepsilon-\beta)+\mathrm{Q} \rho+(\varepsilon-\beta) \mathrm{c}_{\mathrm{f}}\right) / 2 \\
\mathrm{q}_{\mathrm{e}}=\left(\mathrm{Q}+\mathrm{c}(\varepsilon-\beta)-Q \rho+(\varepsilon-\beta) \mathrm{c}_{\mathrm{f}}\right) / 2
\end{gathered}
$$

The final profit of the supply chain:

$\Pi^{\mathrm{YY}}=\left(2 \mathrm{c}^{2}(\beta-\varepsilon)^{2}(\beta+\varepsilon)+2 \mathrm{cQ}\left(\varepsilon^{2}-\beta^{2}\right)+Q^{2}\left(\beta\left(1-2 \rho+2 \rho^{2}\right)-2 \varepsilon(\rho-1)\right)-\frac{2\left(\beta^{2}-\varepsilon^{2}\right)\left(\mathrm{Q}+2 \mathrm{c}(\varepsilon-\beta) \mathrm{c}_{\mathrm{f}}+2(\beta-\varepsilon)^{2}(\mathrm{Q}+2 \mathrm{c}(\varepsilon-\beta)) \mathrm{c}_{\mathrm{f}}+2(\beta-\varepsilon)^{2}(\beta+\varepsilon) \mathrm{c}_{\mathrm{f}}^{2}\right)}{4\left(\beta^{2}-\varepsilon^{2}\right)}\right.$

Compare the cold chain technology between the two sides and do not establish the two sides, put forward the following assumptions and demonstrate.

Assuming that the $2 \mathrm{YY}$ case is compared with the NN case, when $\mathrm{c}_{\mathrm{f}} \leq \mathrm{c} \alpha_{\mathrm{s}}$ and $\mathrm{c}_{\mathrm{f}} \leq \mathrm{c} \alpha_{\mathrm{m}}$, the cold chain technology decreases the selling price of traditional retail channels and e-commerce channels, the total market demand increases.

Prove $\mathrm{p}_{\mathrm{e}}^{\mathrm{YY}}-\mathrm{p}_{\mathrm{e}}^{\mathrm{NN}}=\left(\mathrm{c}_{\mathrm{f}}-\mathrm{c} \alpha_{\mathrm{m}}\right) / 2 \leq 0$, so $\mathrm{p}_{\mathrm{e}}^{\mathrm{YY}} \leq \mathrm{p}_{\mathrm{e}}^{\mathrm{NN}}$, Therefore, the cold chain technology makes the price of e-commerce channel decline. $\mathrm{p}_{\mathrm{t}}^{\mathrm{YY}}-\mathrm{p}_{\mathrm{t}}^{\mathrm{NN}}=$ $\mathrm{c} \beta-\mathrm{c} \varepsilon-Q \rho+2 \beta \mathrm{c}_{\mathrm{f}}-\mathrm{c} \varepsilon \alpha_{\mathrm{m}}-\mathrm{c} \beta \alpha_{\mathrm{s}} / 4 \beta$, because $\mathrm{c} \beta-$ $\mathrm{c} \varepsilon-Q \rho+2 \beta \mathrm{c}_{\mathrm{f}}-\mathrm{c} \varepsilon \alpha_{\mathrm{m}}-\mathrm{c} \beta \alpha_{\mathrm{s}} \geq \mathrm{c} \beta-\mathrm{c} \varepsilon-Q \rho-\mathrm{c}\left(\varepsilon \alpha_{\mathrm{m}}-\right.$ $\left.\beta \alpha_{s}\right)$, and $\mathrm{q}_{\mathrm{t}}^{\mathrm{NN}}>0$, so $\mathrm{c} \beta-\mathrm{c} \varepsilon-\mathrm{Q} \rho-\mathrm{c}\left(\varepsilon \alpha_{\mathrm{m}}-\beta \alpha_{\mathrm{s}}\right)>0$, be $\mathrm{p}_{\mathrm{t}}^{\mathrm{YY}}<\mathrm{p}_{\mathrm{t}}^{\mathrm{NN}}$ establish, The proven cold chain technology has led to a decline in the prices of traditional retail channels. It can be seen that the price of the two channels has declined, so the total market demand will be increased due to the decline in the price of aquatic products.

Hypothesis 2 shows that when the NN situation, $c_{f} \leq$ $\mathrm{c} \alpha_{\mathrm{s}}$ and $\mathrm{c}_{\mathrm{f}} \leq \mathrm{c} \alpha_{\mathrm{m}}$ is satisfied. The cold chain technology reduces the dual channel price of aquatic products, the total market demand expands. However, this is the result of the centralized decision making of the aquatic product channel members. It is necessary to introduce the contract theory with the same result of the centralized decision-making under the decentralized decision-making mechanism. In this paper, this paper uses two pricing methods to analyze the Pareto optimal strategy of the dual channel supply chain of aquatic products. The two pricing method is to divide the price into the fixed cost and the amount of cost. The fixed cost refers to the subsidy for the cold chain logistics cost, the retailer gives the supplier a part of the fixed compensation cost, which refers to the wholesale price that changes with the quantity of the order. On the basis of two pricing methods, two goals can be achieved: first, second pricing methods make the retailer reduce the wholesale price with the increase of the order quantity, thus reducing the retail channel price; second, the retailer gives a certain fixed compensation cost, which can encourage producers to invest in cold chain technology.

Under the two part pricing method, the profit targets of producers and retailers are:

$$
\begin{aligned}
\Pi_{\mathrm{m}}^{\mathrm{YY}}= & (\mathrm{w}-\mathrm{c}) \mathrm{q}_{\mathrm{t}}+\left(\mathrm{p}_{\mathrm{e}}-\mathrm{c}\right) \mathrm{q}_{\mathrm{e}}-\mathrm{c}_{\mathrm{f}}\left(\mathrm{q}_{\mathrm{e}}+\mathrm{q}_{\mathrm{t}}\right)+\mathrm{f} \\
& \Pi_{\mathrm{s}}^{\mathrm{NN}}=\left(\mathrm{p}_{\mathrm{t}}-\mathrm{w}\right) \mathrm{q}_{\mathrm{t}}-\mathrm{f}
\end{aligned}
$$

Suppose $f=\left(p_{t}-w\right) q_{t}-F$, therefore, the producer's profit function is:

$$
\Pi_{\mathrm{m}}^{\mathrm{YY}}=(\mathrm{w}-\mathrm{c}) \mathrm{q}_{\mathrm{t}}+\left(\mathrm{p}_{\mathrm{e}}-\mathrm{c}\right) \mathrm{q}_{\mathrm{e}}-\mathrm{c}_{\mathrm{f}}\left(\mathrm{q}_{\mathrm{e}}+\mathrm{q}_{\mathrm{t}}\right)+\left(\mathrm{p}_{\mathrm{t}}-\mathrm{w}\right) \mathrm{q}_{\mathrm{t}}-\mathrm{F}
$$

The optimal wholesale price and optimal price of the electricity supplier are calculated:

$$
\begin{gathered}
\mathrm{p}_{\mathrm{e}}=\left(\mathrm{c}\left(\beta^{2}-\varepsilon^{2}\right)+\mathrm{Q}(\beta-\beta \rho+\varepsilon \rho)+\left(\beta^{2}-\varepsilon^{2}\right) \mathrm{c}_{\mathrm{f}}\right) / 2\left(\beta^{2}-\varepsilon^{2}\right) \\
\mathrm{p}_{\mathrm{t}}=\left(\mathrm{c}\left(\beta^{2}-\varepsilon^{2}\right)+\mathrm{Q}(\varepsilon+\beta \rho-\varepsilon \rho)+\left(\beta^{2}-\varepsilon^{2}\right) \mathrm{c}_{\mathrm{f}}\right) / 2\left(\beta^{2}-\varepsilon^{2}\right) \\
\mathrm{w}=\left(\mathrm{c}(\varepsilon-\beta)+Q \rho+(\varepsilon-\beta) \mathrm{c}_{\mathrm{f}}\right) / 2 \\
\mathrm{q}_{\mathrm{e}}=\left(\mathrm{Q}+\mathrm{c}(\varepsilon-\beta)-Q \rho+(\varepsilon-\beta) \mathrm{c}_{\mathrm{f}}\right) / 2 \\
\mathrm{q}_{\mathrm{t}}=\left(\mathrm{c}(\varepsilon-\beta)+Q \rho+(\varepsilon-\beta) \mathrm{c}_{\mathrm{f}}\right) / 2
\end{gathered}
$$

At the same time, the maximum profit of the manufacturer, retailer and supply chain is calculated as follows: 


$$
\begin{aligned}
& \Pi_{\mathrm{m}}^{\mathrm{YY}}=\frac{1}{4}\left(4 \mathrm{f}+\left(\mathrm{c}(\beta-\varepsilon)-Q \rho+(\beta-\varepsilon) \mathrm{c}_{\mathrm{f}}\right)\left(\mathrm{c}(2+\beta-\varepsilon)-Q \rho+(\beta-\varepsilon) \mathrm{c}_{\mathrm{f}}+2 \mathrm{c}_{\mathrm{f}}\left(-\mathrm{Q}+2 \mathrm{c}(\beta-\varepsilon)+2(\beta-\varepsilon) \mathrm{c}_{\mathrm{f}}+\right.\right.\right. \\
& \frac{\left(c(\beta-\varepsilon)+Q(\rho-1)+(\beta-\varepsilon) c_{f}\right)\left(c\left(\beta^{2}-\varepsilon^{2}\right)+Q\left(\beta(\rho-1)-\varepsilon \rho+\left(\varepsilon^{2}-\beta^{2}\right) c_{f}\right.\right.}{\beta^{2}-\varepsilon^{2}} \\
& \Pi_{\mathrm{S}}^{\mathrm{YY}}=-\mathrm{f}+\frac{1}{4}\left(( \mathrm { c } ( \beta - \varepsilon ) + Q \rho + ( \varepsilon - \beta ) \mathrm { c } _ { \mathrm { f } } ) \left(\mathrm{c}(\beta-\varepsilon)-Q \rho+(\beta-\varepsilon) \mathrm{c}_{\mathrm{f}}+\frac{\left(\mathrm{c}\left(\beta^{2}-\varepsilon^{2}\right)+Q(\varepsilon+\beta \rho-\varepsilon \rho)+\left(\beta^{2}-\varepsilon^{2}\right) \mathrm{c}_{\mathrm{f}}\right.}{\beta^{2}-\varepsilon^{2}}\right.\right. \\
& \Pi^{\mathrm{YY}}=\left(2 \mathrm{c}^{2}(\beta-\varepsilon)^{2}(\beta+\varepsilon)+2 \mathrm{cQ}\left(\varepsilon^{2}-\beta^{2}\right)+\mathrm{Q}^{2}\left(-2 \varepsilon(\rho-1) \rho+\beta\left(1-2 \rho+2 \rho^{2}\right)\right)-2\left(\beta^{2}-\varepsilon^{2}\right)\left(Q+2 \mathrm{c}(\varepsilon-\beta) \mathrm{c}_{\mathrm{f}}+\right.\right. \\
& \left.2(\beta-\varepsilon)^{2}(\beta+\varepsilon) c_{\mathrm{f}}^{2}\right) / 4\left(\beta^{2}-\varepsilon^{2}\right)
\end{aligned}
$$

Suppose 3 when $\mathrm{f}$ belongs to [a, b], producers and retailers will recognize two pricing contracts.

It is proved that only when the profit of the retailer is not less than the cold chain technology is not invested by both

$$
\mathrm{f} \leq\left(\rho \mathrm{Q}-(\beta-\varepsilon) c-(\beta-2 \varepsilon) \mathrm{c}_{\mathrm{f}}-\mathrm{c} \varepsilon \alpha_{\mathrm{m}}\right)\left(3 \rho \mathrm{Q}-3(\beta-\varepsilon) \mathrm{c}-(3 \beta-2 \varepsilon) \mathrm{c}_{\mathrm{f}}+\mathrm{c} \varepsilon \alpha_{\mathrm{m}}\right) / 16 \beta=\mathrm{a}>0
$$

At the same time, the profit of the manufacturer in building cold chain technology is higher than that of the manufacturer without establishing cold chain technology:

$$
f \geq\left(\rho Q-(\beta-\varepsilon) c+\varepsilon c_{f}-c \beta \alpha_{s}\right)^{2} / 8 \beta=b>0
$$

Therefore, when $f$ belongs to $[a, b]$, producers and retailers will recognize two pricing contracts.

Suppose that 12 in the decentralized decision-making mechanism, two pricing contracts can make the manufacturer and retailer jointly invest the cold chain technology to achieve the supply chain coordination, that is, to achieve the Pareto optimal.

It is proved that the total revenue of the supply chain is equal and the price of the dual channel is equal to the same by comparing the relative variables of the centralized decision and the decentralized decision. And when $\mathrm{f}$ belongs to the [a, b], the two sides of the supply chain are voluntarily practising the contract. Therefore, the two pricing contracts can achieve supply chain coordination.

From hypothesis 11 and hypothesis 12, two pricing contracts can achieve the perfect coordination of supply chain and the best Pareto effect. When $f$ belongs to [f, $f]$, both sides of the supply chain will voluntarily practice the contract and make the producer and retailer gain more profits than their own cold chain technology. The specific value of the $f$ is determined by the relative low position of the manufacturer and the retailer and the bargaining power.

\section{Algorithm Example}

This paper also uses the algorithm to illustrate the previous research conclusions: first, analysis $\alpha_{\mathrm{s}}, \alpha_{\mathrm{m}}$ change on the influence of both sides of the channel supply chain, verification does not establish the correctness of the conclusion when cold chain technology is not established; second, analyze $c_{f}$ the effect of change on the revenue of both sides of channel supply chain, and verify the correctness of the conclusion of cold chain technology. Suppose that the values of each variable are as follows: $Q=700, \rho=0.45, \beta=8, \varepsilon=$ $1, \mathrm{c}=30, \mathrm{c}_{\mathrm{f}}=1, \theta=0.005, \mathrm{l}=2000$

When the manufacturer's food corruption and food safety risk ratio $\alpha_{\mathrm{m}}$ and the retailer change $\alpha_{\mathrm{s}}$, take the variable parties, the profit of both sides of the cold chain technology is higher than that of the cold chain technology. Therefore, it can be obtained: value into the optimal analytical formula of both sides of the two channel supply chain under the condition that the cold chain technology is not established, and $\alpha_{\mathrm{m}}$ and $\alpha_{\mathrm{s}}$ effects on the price and sales are obtained, as shown in the picture.

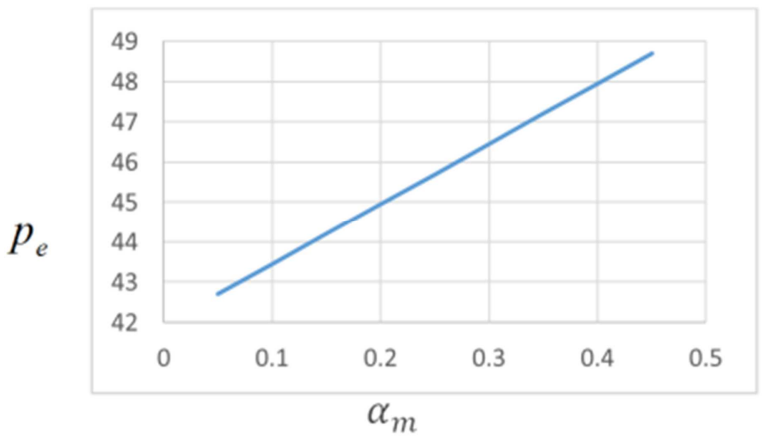

Figure 1. The effect of $\alpha_{m}$ on $p_{e}$.

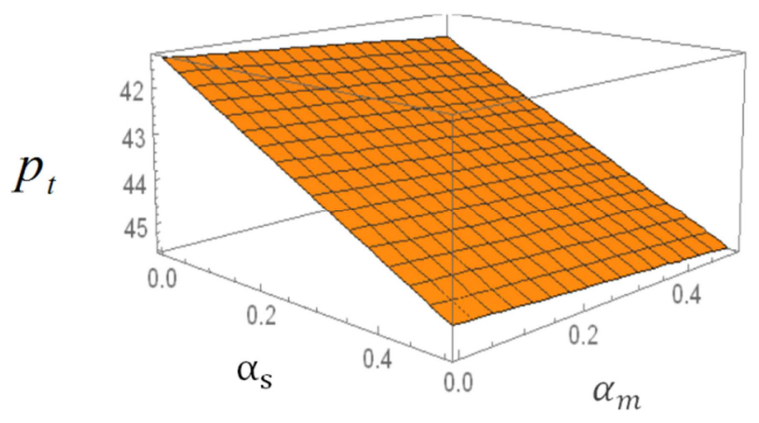

Figure 2. The effect of $\alpha_{m}$ and $\alpha_{s}$ on $p_{e}$.

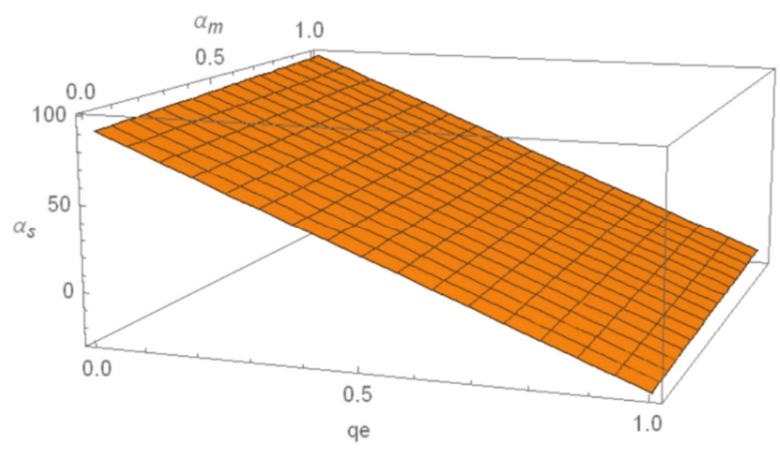

Figure 3. The effect of $\alpha_{m}$ and $\alpha_{s}$ on $q_{e}$. 


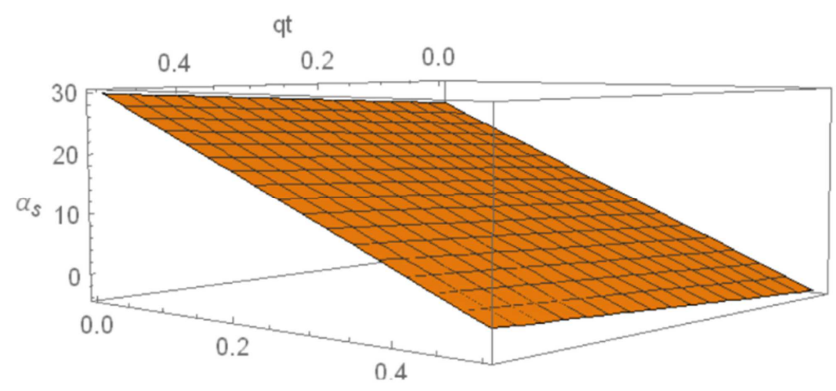

Figure 4. The effect of $\alpha_{m}$ and $\alpha_{s}$ on $q_{t}$.

Figure 1 shows the effect of the proportion of food corruption and food safety risk on the selling price of e-commerce channels. With $\alpha_{m}$ is increased, the price of e-commerce channels also increases, and it can be seen that the price of the channel will not be affected by the proportion of food corruption and food safety risk. Figure 2 is the joint impact of food spoilage and food safety risk on retail channel pricing. It can be seen that the food corruption and food safety risk of producers and retailers have a negative impact on the price of traditional retail channels, and the food corruption and the risk of food safety have reduced the price of traditional retail channels. Figure 3 and Figure 4 are the effects of food corruption and food safety risk on the sales of e-commerce channels. Figure 3 shows that the sales volume of traditional retail channels increases $\alpha_{\mathrm{m}}$ with the increase, but $\alpha_{\mathrm{s}}$ decreases with the decrease. Figure 4 shows that the sales volume of e-commerce channels $\alpha_{m}$ decreases with the increase, but $\alpha_{\mathrm{s}}$ increases with the increase.

\section{Conclusion and Suggestions}

Cold chain technology can effectively reduce the risk of corruption and food safety in dual channel supply chain aquatic products, reduce the losses of manufacturers and retailers and increase the revenue of the whole supply chain, but the input of cold chain technology will also increase the cost of dual channel supply chain, which has an important impact on the decision-making of supply chain. Therefore, how to reasonably invest cold chain technology in the supply chain is the focus of the dual channel supply chain. Through the research on the investment return and coordination of the dual channel supply chain of the cold chain technology, the following conclusions are reached:

Firstly, the impact of aquatic product corruption and food safety risks on the two channel supply chain. The increase of electronic commerce channel and the increase of food safety risk increase the sales price of electronic commerce channels and traditional retail channels, while the increase of the traditional retail channels of aquatic products corruption and the increase of food safety risk only increases the sales price of their own channels, and the sale price of electronic commerce channels is not straight. In terms of the sales of dual channel products, the increase in the risk of aquatic products corruption and food safety in the electronic commerce channels and traditional retail channels makes the sales of the products of their own channels lower, and then the sales of the other channels are increased.
Then the influence of cold chain technology on the two channel supply chain. If both sides do not invest and both sides invest, if the cost of cold chain technology is lower than the cost of aquatic product corruption or food safety problems, cold chain technology can reduce the price of traditional retail channels and e-commerce channels and increase the total market demand. At the same time, in the case of joint investment of cold chain technology, the two pricing methods can be effectively coordinated, and the scope of the retailer's investment subsidy producers is drawn. At this time, the two sides of the supply chain will gain more income than the non investment situation.

This paper assumes that the production capacity of the manufacturer can meet all the needs of the e-commerce channels and traditional retail channels. However, the production capacity and production conditions are limited, and the production capacity will be limited, and there is also the situation that producers and retailers invest in cold chain technology alone. Therefore, when the capacity of the dual channel supply chain is constrained and the two sides invest alone, how the cold chain technology will affect the income of both sides of the dual channel supply chain has become an important direction of the future research.

\section{Acknowledgements}

This article was supported by 2016 Zhanjiang philosophy and Social Sciences Planning Project(7163302) and South China Sea Silk Road Collaborative Innovation Center funded projects.

\section{References}

[1] Taxakis K, Papadopoulos C. A design model and a productionâ "distribution and inventory planning model in multi-product supply chain networks [J]. International Journal of Production Research, 2018, 54(21):6436-6457.

[2] Xu J, Quan X, Liu H. Analysis of the Influencing Factors of Consumers' Trust in the Safety of Aquatic Products Based on DEMATEL Model [J]. Journal of Ocean University of China, 2018.

[3] Tian T, Cao Y W, Liu J X, et al. Discussion on Supervision Work of Aquatic Products Quality Safety in Chengdu City [J]. Modern Agricultural Science \& Technology, 2017.

[4] Li Xiaochuan, Zhai Yuxiu, Wang Lianzhu, et al. Establishing and perfecting some problems of aquatic products traceability system in China $[\mathrm{J}]$. quality and safety of agricultural products, 2006 (4): 14-17.

[5] Ren Xinlin, Ling Wu Hai. Problems and Countermeasures of aquatic products quality and safety $[\mathrm{J}]$. aquaculture, 2011, 32 (12): 48-50.

[6] Li Xiang, song, Huang Lei, et al. Inspiration from China's foreign aquatic product quality and safety traceability system [J]. China fisheries economy, 2010 (4): 92-97.

[7] Zhao H, Liu S, Tian C, et al. An Overview of Current Status of Cold Chain in China [J]. International Journal of Refrigeration, 2018. 
[8] Wu Linhai, Wang Shuxian, Xu Lingling. Traceability of consumption demand in food market: a case study of traceable pork [J]. Journal of public administration, 2013 (3): 119-128.

[9] He Jing, Zhou Peilu. Analysis of decision behavior of marine aquatic product safety traceability system implementation based on FSDN concept [J]. ocean development and management, 2017, 34 (7): 40-47.

[10] Liu Yang. The development status and Countermeasures of fresh agricultural products cold chain logistics under the background of electronic commerce $[\mathrm{J}]$. logistics engineering and management, 2018, 40 (05): 23-24+22.

[11] Xiao, Xinqing, Fu, Zetian, Zhang, Yongjun, et al. SMSâ CQ: A Quality and Safety Traceability System for Aquatic Products in Coldâ Chain Integrated WSN and QR Code [J]. Journal of Food Process Engineering, 2017, 40(1).
[12] Xin-Rong Zhang. Super cold chain-a high quality, energy-efficient, and environment - friendly method [J]. International Journal of Energy Research, 2017, 41(9):1225-1228.

[13] Joshi K, Warby J, Valverde J, et al. Impact of cold chain and product variability on quality attributes of modified atmosphere packed mushrooms (Agaricus bisporus ) throughout distribution [J]. Journal of Food Engineering, 2018, 232.

[14] Ndraha N, Hsiao H I, Vlajic J, et al. Time-temperature abuse in the food cold chain: Review of issues, challenges, and recommendations [J]. Food Control, 2018, 89.

[15] Wang M, Zhao L. Cold chain investment and pricing decisions in a fresh food supply chain [J]. International Transactions in Operational Research, 2018. 